\title{
Profile of antibiotic-resistant and presence of methicillin-resistant Staphylococcus aureus from nasal swab of dogs from several animal clinics in Surabaya, Indonesia
}

\author{
Vega Decline ${ }^{1}$, Mustofa Helmi Effendi² (D), Reina Puspita Rahmaniar ${ }^{3}$, Sheila Marty Yanestria ${ }^{4}$ and Nenny Harijani² \\ 1. Postgraduate Study of Faculty of Veterinary Medicine, Airlangga University, Surabaya, Indonesia; 2. Department \\ of Veterinary Public Health, Faculty of Veterinary Medicine, Airlangga University, Surabaya, Indonesia; 3. Department \\ of Microbiology, Faculty of Veterinary Medicine, Wijaya Kusuma University, Surabaya, Indonesia; 4. Department of \\ Veterinary Public Health, Faculty of Veterinary Medicine, Wijaya Kusuma University, Surabaya, Indonesia. \\ Corresponding author: Mustofa Helmi Effendi, e-mail: mheffendi@yahoo.com \\ Co-authors: VD: vegadecline@yahoo.com, RPR: puspita.reina@gmail.com, SMY: sheila.marty11.sm@gmail.com, \\ $\mathrm{NH}$ : nennyharijani@yahoo.co.id
}

Received: 21-12-2019, Accepted: 18-05-2020, Published online: 24-06-2020

doi: www.doi.org/10.14202/IJOH.2020.90-94 How to cite this article: Decline V, Effendi MH, Rahmaniar RP, Yanestria SM, Harijani N (2020) Profile of antibiotic-resistant and presence of methicillin-resistant Staphylococcus aureus from nasal swab of dogs from several animal clinics in Surabaya, Indonesia, Int. J. One Health, 6(1): 90-94.

\begin{abstract}
Aim: The research was to investigate the antibiotic resistance profile and to screen for methicillin-resistant Staphylococcus aureus (MRSA) from nasal mucosa swab of dogs.

Materials and Methods: The samples were collected from three pet clinics, three K9 units, one veterinary teaching hospital, and one kennel in Surabaya. Of the 50 total samples, 24 confirmed $S$. aureus strains, which were used for antibiotic sensitivity tests using a disk diffusion method and screening of MRSA used oxacillin resistance screening for base (ORSAB).
\end{abstract}

Results: This study showed that there were differences in antibiotic resistance patterns among different locations. Fourteen isolates were screened for MRSA by culture on ORSAB.

Conclusion: MRSA carriage was found on nasal swab of dogs, and dogs can act as reservoir of MRSA for spreading to human health.

Keywords: antibiotic-resistant, dogs, methicillin-resistant Staphylococcus aureus, Staphylococcus aureus.

\section{Introduction}

Staphylococcus aureus is a normal flora that has opportunistic pathogenic properties. Healthy individuals who have $S$. aureus colonization are referred to as careers. $S$. aureus can be also found in dogs at around $20 \%$ [1]. S. aureus infection is one of the important public health problems because the infection cases tend to increase every year. One way to overcome the problem of $S$. aureus infection is to use antibiotics. The intensity of the use of antibiotics that continue to increase and irrationally raise a problem, namely, the emergence of a type of $S$. aureus that is resistant to antibiotics is called methicillin-resistant $S$. aureus (MRSA).

Human-to-animal transmission can occur because currently pets are often considered and treated as family members, thus allowing physical contact between humans and pets that can cause bacterial transmission [2]. This is, of course, a potential public health problem because MRSA from humans can cause infections in pets, and pets can also be a

Copyright: Decline, et al. This article is an open access article distributed under the terms of the Creative Commons Attribution 4.0 International License (http://creativecommons.org/licenses/ by/4.0/), which permits unrestricted use, distribution, and reproduction in any medium, provided you give appropriate credit to the original author(s) and the source, provide a link to the Creative Commons license, and indicate if changes were made. The Creative Commons Public Domain Dedication waiver (http:// creativecommons.org/ publicdomain/zero/1.0/) applies to the data made available in this article, unless otherwise stated. source of MRSA infections in humans, so we must be aware that pets can act as a reservoir in spreading the infection to humans when coming into contact with animals [3].

MRSA infection in dogs is important to consider and investigate, given the similarity in characteristics between MRSA genes found in dogs and humans that indicate infection has occurred are interconnected. However, the mechanism of transmission of infection is still not known with certainty. MRSA strains in dogs are far more resistant to antibiotics than MRSA strains in humans $[2,4]$.

Study to explain the incidence of MRSA in dogs is needed as a reference base that can be used to determine policies for controlling MRSA cases in humans. Research on antibiotic resistance testing and screening tests for MRSA from nasal swab of dogs is expected to provide input or information about antibiotic resistance and screening for MRSA from dogs.

\section{Materials and Methods}

\section{Ethical approval}

Nasal swabs of dogs were used in this study; hence, ethical approval was not necessary. Nasal swab samples were collected from several animal clinics in Surabaya, East Java Province, Indonesia.

\section{Study area study period and sample collection}

Sampling of dog nasal mucosal swabs came from several places, including animal clinics, dog 
kennel, veterinary hospitals, and $\mathrm{K} 9$ units in the City of Surabaya, East Java. Sample testing was carried out in several laboratories, namely, the Department of Veterinary Microbiology, Faculty of Veterinary Medicine, Airlangga University; Department of Veterinary Public Health, Faculty of Veterinary Medicine, Airlangga University; and Airlangga University's Tropical Disease Diagnostic Center. The study was conducted from March 2015 to June 2015.

\section{Bacterial isolates}

Dogs nasal swab samples were collected using sterile cotton sticks and placed in nutrient broth (NB) as a transport medium and stored at $4^{\circ} \mathrm{C}$ in the icebox. $S$. aureus isolation was carried out by streak on mannitol salt agar (MSA) media using sterile cotton swab samples from NB media. Bacterial inoculum on MSA media was incubated at $37^{\circ} \mathrm{C}$ for $24 \mathrm{~h}$ [5].

Isolation and identification of $S$. aureus were determined based on positive results for mannitol fermentation test on MSA media, microscopic examination with Gram staining [6], catalase test, coagulase test, Voges-Proskauer test, and hemolysis test on blood agar (BA) media. Antibiotic resistance tests were carried out using the Kirby-Bauer agar diffusion method and the MRSA screening test was carried out using oxacillin resistance screening agar base (ORSAB) media.

Antibiotic sensitivity test and MRSA confirmation test

Antibiotic resistance test was carried out by inoculating 3-5 S. aureus colonies from MSA media using sterile inoculating loop in a tube containing physiological $\mathrm{NaCl}$, turbidity adjusted to $\mathrm{McF}$ arland $0.5\left(1.5 \times 10^{8} \mathrm{CFU} / \mathrm{mL}\right)[7,8]$. The inoculum in the physiological $\mathrm{NaCl}$ tube was inoculated by stroking a sterile cotton swab on the entire surface of the Mueller-Hinton agar medium. Antibiotic disks were placed on the inoculum cup using antibiotic tweezers, then incubated at $35^{\circ} \mathrm{C}$ for $24 \mathrm{~h}$. Antibiotic resistance test results were read by measuring the diameter of the inhibition zone in the form of clear area around the antibiotic disk in millimeter $(\mathrm{mm})$ scale and adjusted to laboratory standards $[8,9]$.

MRSA confirmation test was done by inoculating $S$. aureus colonies from MSA media to ORSAB media in a streak using sterile inoculating loop, then incubated at $35^{\circ} \mathrm{C}$ for $24 \mathrm{~h}$. Positive results of MRSA were shown by the growth of white bacterial colonies and transparent color changes in ORSAB media to blue [10].

\section{Results}

The results of isolation and identification on 50 samples of dog nasal mucosal swabs showed that 24 samples were $S$. aureus and 14 samples were MRSA.

Isolation and identification of $S$. aureus in dogs nasal mucosal swab samples were carried out by testing the ability of bacteria to ferment mannitol on MSA media, viewing microscopic morphology with
Gram staining, testing catalase production, testing the production of coagulase, testing the production of acetoin, and testing the production of hemolysin in BA media.

Antibiotic resistance tests on $24 \mathrm{~S}$. aureus samples were carried out to determine the presence of MRSA and to determine the effectiveness of an antibiotic as a treatment for bacterial infections. Two samples of dog nasal mucosal swabs originating from the Animal Hospital of Airlangga University were not tested for antibiotic resistance because no colonization of $S$. aureus was found. Example images of antibiotic resistance test results are shown in Figure-1.

Based on the MRSA screening test results from nasal swab of dogs listed in Table-1, 14 of 24 S. aureus samples had positive results on screening tests using ORSAB; therefore, the samples are declared as MRSA. Examples of positive ORSAB test results are shown in Figure-2.

\section{Discussion}

The results of isolation and identification of $S$. aureus in 50 samples of dog nasal mucosal swabs found $24(48 \%)$ samples were positive $S$. aureus.

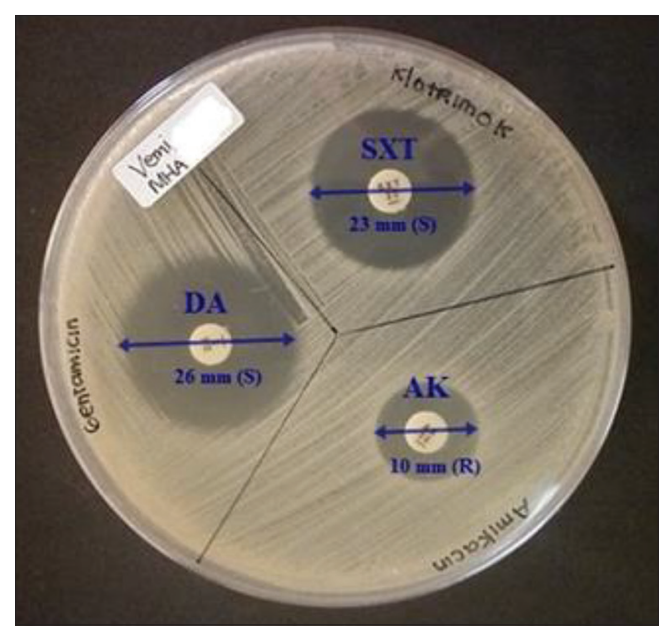

Figure-1: Antibiotic resistance test for Staphylococcus aureus on Mueller-Hinton Agar media. In the picture, S. aureus is sensitive (S) to clindamycin (DA), sensitive (S) to cotrimoxazole (SXT), and resistant (R) to amikacin (AK).

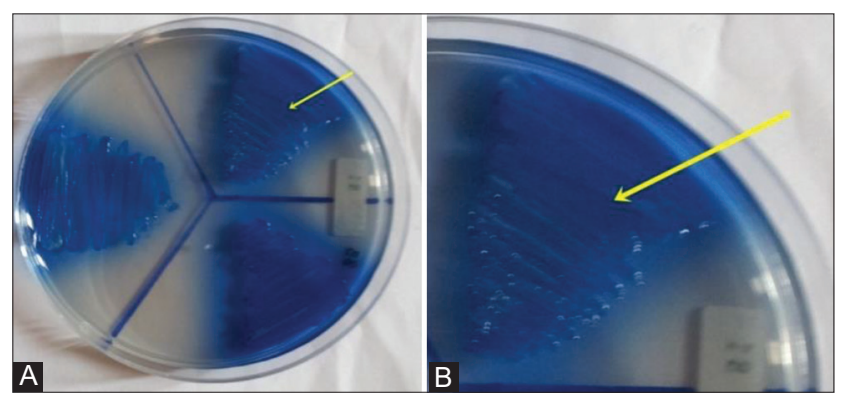

Figure-2: Methicillin-resistant Staphylococcus aureus (MRSA) confirmation test on oxacillin resistance screening for base (ORSAB) media. Figure $A$ is a form of MRSA colony growth on a surface area of ORSAB media. Figure $B$ is an enlargement of the growth form of the MRSA colony from Figure A. In the designated image, a blue MRSA colony is seen. 
Table-1: Results of percentage antibiotic resistance test in percentage (\%) and screening for MRSA from dog nasal mucosal swabs.

\begin{tabular}{|c|c|c|c|c|c|c|c|c|}
\hline \multirow[t]{2}{*}{ Resistant/MRSA } & \multicolumn{8}{|c|}{ Name of pet clinic location } \\
\hline & $\mathbf{A}$ & B & C & D & $\mathbf{E}$ & $\mathbf{F}$ & G & $\mathbf{H}$ \\
\hline AK (Amikacin) & $100 \%$ & $0 \%$ & $0 \%$ & $0 \%$ & $60 \%$ & $100 \%$ & $33.3 \%$ & $72.7 \%$ \\
\hline P (Penicillin G) & $100 \%$ & $100 \%$ & $0 \%$ & $0 \%$ & $80 \%$ & $100 \%$ & $66.7 \%$ & $90.9 \%$ \\
\hline C (Chloramphenicol) & $100 \%$ & $50 \%$ & $100 \%$ & $0 \%$ & $20 \%$ & $0 \%$ & $0 \%$ & $0 \%$ \\
\hline DA (Clindamycin) & $100 \%$ & $50 \%$ & $100 \%$ & $0 \%$ & $40 \%$ & $0 \%$ & $0 \%$ & $36.4 \%$ \\
\hline SXT (Cotrimoxazole) & $0 \%$ & $0 \%$ & $0 \%$ & $0 \%$ & $0 \%$ & $0 \%$ & $0 \%$ & $0 \%$ \\
\hline E (Erythromycin) & $100 \%$ & $50 \%$ & $100 \%$ & $0 \%$ & $20 \%$ & $0 \%$ & $33.3 \%$ & $18.2 \%$ \\
\hline CN (Gentamicin) & $100 \%$ & $50 \%$ & $0 \%$ & $0 \%$ & $40 \%$ & $100 \%$ & $33.3 \%$ & $18.2 \%$ \\
\hline F (Nitrofurantoin) & $0 \%$ & $0 \%$ & $0 \%$ & $0 \%$ & $0 \%$ & $0 \%$ & $0 \%$ & $27.3 \%$ \\
\hline TE (Tetracycline) & $100 \%$ & $0 \%$ & $100 \%$ & $0 \%$ & $100 \%$ & $0 \%$ & $0 \%$ & $36.4 \%$ \\
\hline OX (Oxacillin) & $100 \%$ & $100 \%$ & $0 \%$ & $0 \%$ & $20 \%$ & $0 \%$ & $0 \%$ & $27.3 \%$ \\
\hline MRSA & 1 & 2 & 1 & 0 & 4 & 0 & 2 & 4 \\
\hline
\end{tabular}

Percentage (\%) resistance of Staphylococcus aureus isolates. MRSA: Methicillin-resistant Staphylococcus aureus

The percentage of MRSA isolates was 14/50 (28\%) of the total number of nasal swab of dogs and $14 / 24$ $(58.33 \%)$ of $S$. aureus isolates. Researchers mention that $S$. aureus carrier infections in dogs range from $20 \%$, but can reach $70 \%-88 \%[1,11]$. This was similar to the level of resistance in clinical isolates that have been previously reported by many authors: $45.5 \%$ in Japan [12], 61\% in Taiwan [13], 61.5\% in Sudan [14], and $61.8 \%$ in the US [15]. S. aureus bacteria that can be isolated and identified in this study increasingly confirm that the dog's nose has a carrier infection and can be a source of transmission of bacterial infections.

Based on the percentage of antibiotic resistance test results in Table-1, it can be seen if each origin has a resistance to one type of antibiotic except for pet clinic location D, due to $S$. aureus isolate was not found. A high resistance rate against a certain type of antibiotic can indicate its frequent use so that the antibiotic becomes ineffective as a therapy for bacterial infections.

According to Findik et al. [4], S. aureus resistance to penicillin is a common thing, with a resistance level of almost 90\%. Valentina and dan Lestari [16] wrote that in the Indonesian human community, the highest frequency of resistance is against tetracycline, while the lowest is resistance to oxacillin.

The positive MRSA screening results confirm that healthy dogs can carry asymptomatic MRSA colonies. Faires et al. [2] stated that MRSA can be identified in healthy dogs without showing clinical manifestations. MRSA colonization will not cause serious illness if it occurs in humans and animals with normal conditions (healthy), but can cause serious to life-threatening illness if it occurs in individuals who have low immunity. Transmission of MRSA in dogs occurs through direct contact with bacteria found in fellow animals, humans, and contaminated environments [17].

The interaction between animals and humans has an important role in the spread of MRSA because most dogs get MRSA through human contact. MRSA is not found in wild dogs, this is evidence that contact with humans has an important role in the transmission of MRSA. However, there are still other factors such as genetics and the environment that can influence the transmission of infection [4]. Based on this study, 14 were positive for MRSA. Grema et al. [18] stated that MRSA is basically $S$. aureus, which has methicillin resistance. This study seems to be in accordance with the previous studies that successfully isolated MRSA in dogs. European studies have found MRSA matches in dogs and cats that are identical to owners and infected pets. The dominance of human MRSA strains in household pets shows that animals become infected through contact with infected people, and this shows that pets can repropagate MRSA to humans or other species $[17,19]$.

The results of this study explain that MRSA can be found in nasal swab samples from healthy dogs. This is consistent with the results of research by Faires et al. [2], which states that MRSA is increasingly identified in dogs and cats with infections as well as healthy dogs and cats. As a result of frequent physical contact between humans and pets that can facilitate the occurrence of MRSA transmission. This is a potential health problem because MRSA from humans can cause infections in pets, and pets may be a source of MRSA for infections in humans.

The spread of MRSA itself occurs either through direct contact with an infected person or through direct contact with surfaces or objects that were previously contaminated by an infected individual. Animals with MRSA infections can function as a reservoir for bacterial or human transmission by bacteria, therefore controlling and preventing MRSA transmission from animals to animals, as well as from animals to humans must be carried out by applying clean living habits to prevent bacterial outbreaks. MRSA in animals and humans can be prevented by early detection [20-22].

No effective MRSA infection therapy has been found yet, so control and prevention measures are needed to overcome the problem of MRSA spread. MRSA infection control and prevention programs can be carried out with early detection of MRSA with microbiological surveillance, maintaining hand hygiene, counseling, use of safety standards, rational 
use of antibiotics, and isolation room for sufferers of infection [23].

\section{Limitation of the study}

The number of healthy dogs who meet the requirements as the target sample in several pet clinics is limited; therefore, sample size 50 is enough. Some suggestions for future research could be useful to make in the end, for example, to extend the sample size, to include cats, or to compare samples of dogs and owners.

\section{Conclusion}

Based on the results of research on several antibiotic resistance tests and screening tests for MRSA from dog nasal mucosal swabs, it can be concluded that the study dog's nasal mucosa has MRSA career colonization can act as reservoir for spreading to human health and that different samples have a different picture of antibiotic resistance.

\section{Authors' Contributions}

MHE: Developed the concept, wrote the protocol, drafted the manuscript, and final proofreading of the manuscript. VD and RPR: Planned and coordinated the experiments during fieldwork and laboratory analysis, collected the data during fieldwork, and advised on the manuscript formatting. SMY and $\mathrm{NH}$ : Interpretation and description of analyzed data read and corrected the manuscript on technical and language part. All authors read and approved the final manuscript.

\section{Acknowledgments}

The authors are very grateful for the financial support received from the Rector of Universitas Airlangga on Hibah Mandat Research Grant, Indonesia, grant number: 266/UN3.14/LT/2015. Finally, we are grateful to the dog's keepers for allowing us to use their dogs during samples collection.

\section{Competing Interests} work.

There are no competing interests related to this

\section{Publisher's Note}

Veterinary World (Publisher of International Journal of One Health) remains neutral with regard to jurisdictional claims in published institutional affiliation.

\section{References}

1. Gomez-Sanz, E., Torres, C., Ceballos, S., Lozano, C. and Zarazaga, M. (2013) Clonal dynamics of nasal Staphylococcus aureus and Staphylococcus pseudintermedius in dog-owning household members, detection of MSSA ST398. J. PLoS One, 8(7): 10.

2. Faires, M.C., Traverse, M., Tater, K.C., Pearl, D.L. and Weese, J.S. (2010) Methicillin-resistant and susceptible Staphylococcus aureus infections in dogs. J. Emerg. Infect. Dis., 16(1): 69-75.

3. Sudhakara, R.B., Kumari, K. and Sivajothi, S. (2016)
Methicillin-resistant Staphylococcus aureus (MRSA) isolated from dogs with recurrent pyoderma. J. Dairy Vet. Anim. Res., 3(2): 62-65.

4. Findik, A., Ciftci, A., Onyay, T., Sezener, M.G., Kocak, Y. and Gulhan, T. (2018) Determination of methicillin resistance and some genotypic characteristics of staphylococci isolated from dogs and their owners. Turk. J. Vet. Anim. Sci., 42(6): 549-555.

5. Effendi, M.H., Hisyam, M.A.M., Hastutiek, P. and Tyasningsih, W. (2019) Detection of coagulase gene in Staphylococcus aureus from several dairy farms in East Java, Indonesia, by polymerase chain reaction. Vet. World, 12(1): 68-71.

6. Effendi, M.H., Oktavianto, A. and Hastutiek, P. (2018) Tetracycline resistance gene in Streptococcus agalactiae isolated from bovine subclinical mastitis in Surabaya, Indonesia. Philipp. J. Vet. Med., 55(SI): 115-120.

7. Clinical and Laboratory Standards Institute. (2017) M100 Performance Standards for Antimicrobial. 27 $7^{\text {th }}$ ed. Clinical and Laboratory Standards Institute, United States.

8. Vandepitte, J., Yerhaegen, J., Engbaek, K., Rohner, P., Piot, P. and dan Heuck, C.C. (2011) Basic Laboratory Procedures in Clinical Bacteriology. $2^{\text {nd }}$ ed. Penerbit Buku Kedokteran EGC, Jakarta. p88-89, 97-99.

9. Clinical and Laboratory Standards Institute. (2012) Performance Standards for Antimicrobial Disk Diffusion Susceptibility Testing; $17^{\text {th }}$ Informational Supplement. Approved Standard M100-17, Clinical and Laboratory Standards Institute, Wayne, PA.

10. Tong, S.Y.C., Davis, J.S., Eichenberger, E., Holland, T.L. and Fowler, V.G. (2015) Staphylococcus aureus infections: Epidemiology, pathophysiology, clinical manifestations, and management. Clin. Microbiol. Rev., 28(3): 603-661.

11. Manian, F.A. (2003) Asymptomatic nasal carriage of mupirocin-resistant, methichillin-resistant Staphylococcus aureus (MRSA) in pet dog associated with MRSA infection in household contacts. Brief report. J. Clin. Infect. Dis., 36(2): 26-28

12. Kunishima, H., Yamamoto, N. and Kobayashi, T. (2010) Methicillin-resistant Staphylococcus aureus in a Japanese community hospital: 5-year experience. J. Infect. Chemother., 16(6): 414-417.

13. Huang, A.H., Yan, J.J. and Wu, J.J. (2000) Rapid dissemination of Staphylococcus aureus with classic oxacillin resistance phenotype at a new university hospital. J. Hosp. Infect., 44(4): 309-315.

14. Elhassan, M.M., Ozbak, H.A., Hemeg, H.A., Elmekki, M.A. and Ahmed, L.M. (2015) Absence of the mecA gene in methicillin-resistant Staphylococcus aureus isolated from different clinical specimens in Shendi city, Sudan. BioMed Res. Int., 2015: 1-5.

15. Jarvis, W.R., Jarvis, A.A. and Chinn, R.Y. (2012) National prevalence of methicillin-resistant Staphylococcus aureus in patients at United States health care facilities, 2010. Am. J. Infect. Control, 40(3): 194-200.

16. Valentina, A.S. and dan Lestari, E.S. (2010) Effect of Socio-economic Factors on Colonization and Patterns of Staphylococcus aureus Resistance in Research Elementary Students in Three Elementary Schools in Semarang City. Thesis. Fakultas Kedokteran Universitas Diponegoro, Semarang.

17. Aires-de-Sousa, M. (2017) Methicillin-resistant Staphylococcus aureus among animals: Current overview. Clin. Microbiol. Infect., 23(6): 373-380.

18. Grema, H.A., Geidam, Y.A., Gadzama, G.B., Ameh, J.A. and Suleiman, A. (2015) Methicillin-resistant Staphyloccus aureus (MRSA): A review. Adv. Anim. Vet. Sci., 3(2): 79-98.

19. Oliveira, C.J.B., Tiao, N., de Sousa, F.G.C., de Moura, J.F.P., Filho, L.S. and Gebreyes, W.A. (2016) Methicillin-resistant Staphylococcus aureus from Brazilian dairy farms and identification of novel sequence types. Zoonoses Public Health, 63(2): 97-105. 
20. Wongwanich, S., Tishyadhigama, P., Paisomboon, S., Ohta, T. and Hayashi, H. (2000) Epidemiological analysis of methicillin-resistant Staphylococcus aureus in Thailand. Southeast Asian J. Trop. Med. Public Health, 31(1): 72-76.

21. Gopal, S. and Divya, K.C. (2017) Can methicillin-resistant Staphylococcus aureus prevalence from dairy cows in India act as potential risk for community-associated infections? A review. Vet. World, 10(3): 311-318.

22. Tyasningsih, W., Effendi, M.H., Budiarto, B. and Syahputra, I.S. (2019) Antibiotic resistance to
Staphylococcus aureus and methicillin-resistant Staphylococcus aureus (MRSA) isolated from dairy farms in Surabaya, Indonesia. Indian Vet. J., 96(11): 27-31.

23. Rehm, S.J.H., Boucher, D., Levine, M., Champion, B.I., Eisenstein, G.A., Vigliani, G.R. and Abrutyn, E. (2008), Daptomycin versus vancomycin plus gentamycin for treatment of bacteraemia and endocarditis due to Staphylococcus aureus: Subset analysis of patients infected with methicillin-resistant isolates. J. Antimicrob. Chemother., 62(6): 1413-1421.

$* * * * * * * *$ 